\title{
Atuação de enfermeiras no campo da regulação da fecundidade em um serviço público de saúde*
}

\author{
PRACTICE OF NURSES IN FERTILITY REGULATION IN A PUBLIC HEALTH CARE INSTITUTION \\ ACTUACIÓN DE ENFERMERAS EN EL CAMPO DE LA REGULACIÓN DE LA FECUNDIDAD \\ EN UN SERVICIO PÚBLICO DE SALUD
}

\author{
Edméia de Almeida Cardoso Coelho ${ }^{1}$, Rosa Maria Godoy Serpa da Fonseca ${ }^{2}$
}

\begin{abstract}
RESUMO
Trata-se de um artigo extraído de Tese de

Doutorado que teve como objetivo conhecer a prática das enfermeiras na assistência à mulher em um serviço público de saúde. Traz um recorte dessa prática, referente à atuação das enfermeiras no campo da regulação da fecundidade. $O$ material empírico foi produzido por meio de oficinas de reflexão e, analisado pela técnica de análise do discurso, sob a abordagem teórica de gênero. A análise revelou que, em sua prática, as enfermeiras valorizam as vivências sexual e reprodutiva das usuárias, mas o poder institucional, neste incluido o poder médico, limita a participação das enfermeiras na construção da autonomia e da liberdade reprodutiva das mulheres.
\end{abstract}

\section{PALAVRAS-CHAVE \\ Anticoncepção. \\ Política de saúde. \\ Cuidados de enfermagem. \\ Enfermagem em saúde pública.}

\author{
ABSTRACT \\ This article is based on a \\ doctoral dissertation that \\ investigated the behavior of \\ nurses concerning women's \\ health in a public health care \\ institution. It presents an \\ experience in this practice \\ regarding the actions of \\ fertility regulation. The \\ empirical data were obtained \\ through reflection workshops \\ and they were analyzed \\ according to the discourse \\ analysis technique and the \\ gender theoretical approach. \\ The analysis showed that in \\ their practice, nurses value \\ women's sexual and \\ reproductive experiences, \\ however, the institutional \\ power, including here medical \\ power, restrain their \\ participation in the \\ development of the autonomy \\ and reproductive freedom of \\ women.
}

\section{KEYWORDS \\ Contraception. \\ Health policy. \\ Nursing care. \\ Public health nursing.}

\begin{abstract}
RESUMEN
Este artículo fue producido a partir de una Tesis de Doctorado que investigó la práctica de enfermeras en la asistencia a la mujer en un Servicio Público de Salud. Es una experiencia de la práctica referente a la actuación de las enfermeras en el campo de la regulación de la fertilidad. El material empírico fue obtenido por medio de talleres de reflexión y analizado por la técnica de Análisis del Discurso bajo un abordaje teórico de género. El análisis demostró que en su práctica las enfermeras valoran las experiencias sexuales $y$ reproductivas de las mujeres aunque el poder institucional, incluso el poder médico, limita la participación de las enfermeras en la construcción de la autonomía y de la libertad de reproducción de las mujeres.
\end{abstract}

\section{PALABRAS CLAVE \\ Anticoncepción. \\ Politica de salud. Atención de enfermería. Enfermería en salud publica.}

\footnotetext{
* Trabalho apresentado no $53^{\circ}$ Congresso Brasileiro de Enfermagem (CBEn), tendo como base a Tese de Doutorado intitulada "Enfermeiras que cuidam de mulheres: conhecendo a prática sob o olhar de gênero", Escola de Enfermagem da USP (EEUSP), 2001.

1 Enfermeira. Doutora em Enfermagem pela EEUSP. Professora Adjunto I do Departamento de Enfermagem de Saúde Pública e Psiquiatria da Universidade Federal da Paraíba edalcoelho@hotmail.com

2 Enfermeira. Doutora em Enfermagem pela EEUSP. Professora Titular do Departamento de Enfermagem de Saúde Coletiva da EEUSP.

rmgsfon@usp.br
} 
Edméia de Almeida C Coelho Rosa Maria G S Fonseca

\footnotetext{
(a) Embora planejamento familiar constitua uma expressão conservadora, dotada de valor moral, e que traz implícito um modelo de família ideologizado e naturalizado como lugar de realização das mulheres, constitui, na perspectiva do PAISM, um avanço significativo na construção da cidadania feminina e uma forma de diálogo do movimento feminista com o Governo para tratar de questões relativas à contracepção.
}

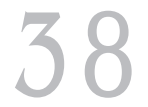

Rev Esc Enferm USP 2004; 38(1): 37-45.

\section{INTRODUÇÃO}

Este artigo foi produzido a partir de uma categoria empírica de análise, que integra investigação mais ampla, desenvolvida na tese de doutorado Enfermeiras que cuidam de mulheres: conhecendo a prática sob o olhar de gênero ${ }^{(1)}$. A tese foi motivada por pesquisa anterior ${ }^{(2)}$, em que foi analisada a política de planejamento familiar em João Pessoa- PB, a partir dos discursos das equipes multiprofissionais de seis serviços públicos considerados de referência para a saúde da mulher, dos profissionais que estão à frente das políticas públicas de saúde na Secretaria Municipal de Saúde, Secretaria de Estado da Saúde e de mulheres usuárias dos serviços selecionados para a pesquisa.

Nos serviços estudados, o planejamento familiar $^{(a)}$, introduzido nas práticas profissionais, desde 1984, pelo Programa de Assistência Integral à Saúde das Mulheres (PAISM) como direito a ser viabilizado pelo Estado, majoritariamente se reduzia a manobras controlistas e as mulheres eram sujeitos passivos no processo decisório da contracepção. Nesses serviços, o espaço das mulheres era restrito devido a informações limitadas, dificuldades de acesso aos métodos contraceptivos pelas freqüentes faltas desses insumos e por opções pouco diversificadas, além de as atividades serem orientadas sobretudo pela visão técnica, distanciandose do contexto de vida das mulheres ${ }^{(3-4)}$.

Todavia, a pesquisa apontou para uma ampliação da atuação profissional, especialmente a das enfermeiras. Em um dos serviços estudados, as enfermeiras, além de quantitativamente mais representadas, defendiam a regulação da fecundidade como direito e identificavam-se como responsáveis diretas pela assistência às mulheres em planejamento familiar. Contraditoriamente, mostravam-se insatisfeitas com a prática, que faziam entender ser dependente do saber e poder médicos, sendo seu contato com as mulheres posterior às prescrições médicas, agindo segundo suas ordens que eram centradas na medicalização do corpo da mulher.

O interesse pela atuação qualitativa das enfermeiras, levou-nos a questionar os limites da sua prática num contexto em que, embora se identificassem como responsáveis pelo planejamento familiar e o defendessem como direito, as mulheres usuárias eram negadas como sujeitos capazes de decidir politicamente sobre o seu corpo. Diante dessa realidade, decidimos conhecer a prática das enfermeiras nos cuidados à saúde das mulheres naquele serviço, nos campos de assistência em que atuam, por considerar que, em todos eles intercruzam-se a vivência sexual e a vivência reprodutiva das mulheres, representando espaços em que também se materializam saberes e poderes.

O material empírico produzido para a tese, inicialmente, aborda as relações que as enfermeiras estabelecem institucionalmente para a efetivação da prática e, num segundo momento, refere-se à atuação das enfermeiras na assistência à mulher, no pré-natal, no planejamento familiar e na prevenção e controle do câncer de colo uterino e de mama, envolvendo atividades clínicas e educativas. Selecionamos, para divulgação neste artigo, a prática das enfermeiras no âmbito da regulação da fecundidade.

\section{METODOLOGIA}

O estudo foi desenvolvido sob a abordagem teórica de gênero, por entendermos que o trabalho de enfermagem é predominantemente feminino, e que

gênero, materializado na divisão social do trabalho e articulado com outras categorias sociais, constitui e regula os saberes e as práticas, as identidades sócio-profissionais, bem como as instituições sociais e políticas no âmbito da saúde, por onde a enfermagem se produz e se movimenta ${ }^{(5)}$.

Trata-se de uma pesquisa qualitativa. Esta responde a questões muito particulares, trabalhando

com o universo de significados, motivos, aspirações, crenças, valores e atitudes, o que corresponde a um espaço mais profundo das relações, dos processos e dos fenômenos que não podem ser reduzidos à operacionalização de variáveis ${ }^{(6)}$.

O estudo foi desenvolvido em um centro de assistência especializada à mulher, integrante do Sistema Único de Saúde (SUS), em João Pessoa-PB. O serviço de saúde, cenário do estudo, foi criado na década de 1970 e é referência na atenção básica e especializada à saúde da mulher, no pré-natal, planejamento familiar, prevenção e controle 
do câncer de colo uterino e de mama, oferecendo serviços laboratoriais e exames ultrassonográficos, tendo convênio com clínicas especializadas para exames radiológicos. A equipe multiprofissional para atendimento à mulher é formada por enfermeiras, médicos, assistentes sociais, psicólogas e nutricionistas. As enfermeiras, participantes deste estudo, têm tempo de atuação na área variando de três a vinte e três anos e seu vínculo com as ações no âmbito da regulação da fecundidade foi iniciado por ocasião da divulgação do PAISM, quando fizeram capacitação técnica, com o objetivo de assistir as mulheres, segundo os princípios do Programa.

Para a realização da pesquisa, inicialmente, foram feitos contatos com a diretoria do serviço e com a chefia de enfermagem e, posteriormente, com as enfermeiras assistenciais. A nossa inserção no campo de pesquisa deu-se em torno de trinta dias decorridos do primeiro contato até o início da coleta de dados, o que possibilitou nossa aproximação com o contexto mais amplo da assistência à saúde da mulher naquele serviço. O universo empírico do estudo constituiu-se das nove enfermeiras que prestam assistência à saúde da mulher, sendo sete enfermeiras, os sujeitos sociais que aceitaram participar da pesquisa, segundo sua disponibilidade e interesse pelos objetivos da investigação. Após aceitarem participar do estudo, leram e assinaram o Termo de Consentimento Livre e Esclarecido, elaborado segundo critérios da Resolução 196/96 do Conselho Nacional de Saúde para pesquisa com seres humanos, previamente aprovado pelo Comitê de Ética em Pesquisa da Escola de Enfermagem da USP. Foram garantidos, o anonimato pelo uso de nomes fictícios, a liberdade de desistir de participar da pesquisa, em qualquer momento, e o livre acesso ao conteúdo do estudo e às pesquisadoras.

Considerando que a temática abordada é parte de uma pesquisa mais ampla, neste artigo não há referência aos discursos de duas participantes, cujos depoimentos foram centrados em outros aspectos explorados na pesquisa, estando presentes em outras categorias analisadas.

O material empírico foi produzido por meio de oficinas de reflexão ${ }^{(7)}$, entendidas como instâncias de reflexão e ação onde se buscam explicações para a realidade em seus aspectos estruturais, fazendo-se confluir teoria e prática e sendo produzidos conhecimentos novos por meio do trabalho coletivo ${ }^{(8)}$. Foram utilizadas dinâmicas grupais que permitiram reflexões e discussões, sendo a elas associada a técnica de observação, que, embora implícita no trabalho das oficinas, foi utilizada de forma sistemática, possibilitando nossa aproximação da perspectiva do grupo e do fenômeno pesquisado.

O processo de produção do material empírico foi coordenado pela pesquisadora autora da tese referida, com a colaboração de docente com experiência em saúde da mulher e em trabalhos com oficinas de reflexão. Os discursos das participantes do estudo foram gravados em fitas cassete, posteriormente, transcritos na íntegra pelas pesquisadoras e, o material das observações registrado em diário de campo. Foram realizadas quatro oficinas no período de 30 dias dos meses de setembro/outubro de 2001, com duração de quatro horas cada e intervalo semanal entre os encontros. O processo completo das oficinas foi desenvolvido com um grupo piloto formado por sete enfermeiras mestrandas e/ou professoras com projetos de pesquisa na área de saúde da mulher, antecedendo o processo desenvolvido com o grupo selecionado para participar da pesquisa.

Para a análise dos dados, utilizou-se a técnica de análise do discurso, na perspectiva de Fiorin, que tem como princípio básico reconhecer, no texto, o nível mais abstrato, temático, que lhe dá coerência. Para o autor, a reiteração, a redundância, a repetição, a recorrência de traços semânticos ao longo do discurso, entre outros fatores, dão coerência ao texto. Para se perceber a reiteração, deve-se

\footnotetext{
tentar agrupar os elementos significativos (figuras ou temas) que se somam ou se confirmam num mesmo plano do significado (...) percorrer o texto inteiro, tentando localizar todas as recorrências, isto é, todas as figuras e temas que conduzem a um mesmo bloco de significação. Essa recorrência determina o plano de leitura do texto (...). Quando se agrupam figuras a partir de um elemento significativo, estamos perto de depreender o tema do texto ${ }^{(9)}$.
}

Atuação de enfermeiras no campo da regulação da fecundidade em um serviço público de saúde 
Edméia de Almeida C Coelho Rosa Maria G S Fonseca
A identificação dos temas elucida valores, crenças, anseios, expectativas, que revelam a visão de mundo do enunciador. Desse modo, o texto pode ser compreendido como um tecido no qual procuramos a organização de seus fios, suas tramas, ou seja, o arranjo que lhes confere significado ${ }^{(9-11)}$.

Neste estudo, a construção das categorias empíricas deu-se pela articulação de figuras e temas na construção de frases temáticas sob orientação de uma pesquisadora com conhecimento e prática em análise do discurso. As frases temáticas, articuladas aos objetivos da pesquisa e ao eixo teórico, formaram categorias empíricas de análise, no entanto, optamos pelo uso dos discursos diretos no relatório de tese. Os depoimentos das enfermeiras referentes à prática no campo da regulação da fecundidade referiram-se a atividades clínicas e educativas e, o processo analítico que evidenciou os temas resultou em dois eixos temáticos.

\section{Eixo 1: Assistência à mulher em planejamento familiar como espaço de relações entre sujeitos}

$\mathrm{Na}$ atualidade, o planejamento familiar, como política de Estado, faz parte de uma proposta ampla de saúde sexual e reprodutiva que envolve aspectos biológicos, psicológicos, familiares, sociais, culturais e políticos. Em seus princípios, valoriza a vida, as relações pessoais e a expressão das subjetividades, razão pela qual, no campo das práticas em saúde, as mulheres precisam ser consideradas em seus contextos de vida.

No Brasil, essa perspectiva remete ao PAISM, no qual a atuação dos profissionais de saúde, no que se refere ao planejamento familiar,

deve estar pautada no pressuposto básico de que todas as pessoas têm o direito à livre escolha dos padrões de reprodução que lhes convenham como indivíduos ou como casais ${ }^{(12)}$.

Desse modo, a assistência à mulher, no campo da regulação da fecundidade,

pressupõe a oferta de todas as alternativas possíveis em termos de métodos anticoncepcionais reversíveis, bem como o conhecimento de suas indicações e implicações de uso, garantindo à mulher ou ao casal os elementos necessários para a opção livre e consciente do método que a eles melhor se adapte ${ }^{(12)}$.
No serviço em que foi realizado o estudo, o atendimento pelas enfermeiras, na área de planejamento familiar, tem possibilitado às mulheres um espaço de discussão de suas vivências sexuais e reprodutivas. Para as enfermeiras, esse é um momento privilegiado para desenvolver o cuidar centrado na perspectiva relacional; para as mulheres, é uma oportunidade de se fazerem sujeitos. $\mathrm{O}$ discurso a seguir, aponta essa direção:

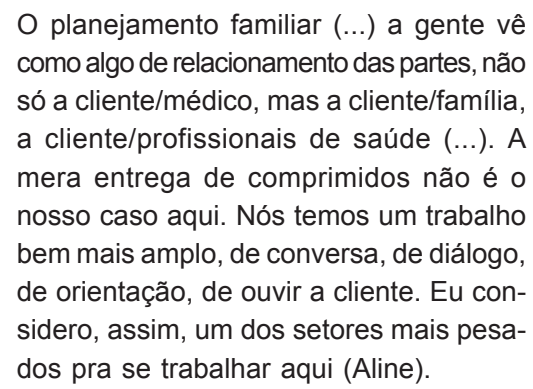

O discurso de Aline revela um espaço aberto para compreender o contexto de vida das clientes aproximando-se da proposta do PAISM, em que o trabalho com mulheres deve propiciar a escuta, a reflexão e a discussão de suas dificuldades. Naquele serviço, o trabalho em planejamento familiar é limitado ao espaço das consultas mas, uma vez valorizado o contexto de vida das mulheres, os padrões da competência técnica e da neutralidade científica modificam-se, na medida em que, associa-se ao cuidar instrumental a expressividade, dimensão de acolhimento e afeto às mulheres.

A mesma enfermeira amplia seu depoimento afirmando:

\footnotetext{
É no planejamento familiar aonde vão os problemas dos mais complexos possíveis de casais, de relacionamento familiar(...). A gente sai daqui realmente pesada em vários dias, porque quer ajudar a cliente, mas a gente não tem muitos caminhos a percorrer aqui dentro (Aline).
}

No tocante aos poucos caminhos a percorrer, torna-se importante considerar que cada situação que se apresenta às enfermeiras traz a singularidade de uma vida de mulher, e "em cada ato, o outro é uma pessoa em toda a sua integralidade e complexidade"(13). Além disso, sabe-se que a organização dos serviços públicos de saúde no Brasil, a formação dos profissionais e a implementação das políticas públicas são orientadas por um modelo de atenção que privilegia a dimensão técnica e 
distancia-se da perspectiva interdisciplinar. Assim, questões de caráter estrutural e conjuntural retardam o enfrentamento das contradições, somando-se a elas a pouca interação entre a equipe, como lê-se no depoimento a seguir:

Aqui, cada um trabalha de acordo com sua cabeça, não há rotina de serviço preestabelecida, reuniões, cobrança, como deveria ser no serviço público, cada profissional age de acordo com sua mentalidade (Eloísa).

Desse modo, aos encaminhamentos feitos pelas enfermeiras correspondem ações isoladas que não se revertem numa perspectiva de resgate da integralidade da assistência às mulheres e, estas se vinculam às enfermeiras porque na relação que estabelecem há espaço para o diálogo:

Nós temos o cuidado de encaminhar ao médico, à psicóloga se for o caso de algum problema psicológico e à assistente social, o que for da área competente... Mas a ligação da cliente é com a enfermagem... Parece-me que se tirar a enfermagem do ciclo do planejamento familiar, o serviço acaba (Aline).

A relação das enfermeiras com as clientes diferencia-se de outras relações profissionais tanto pela indissociabilidade identitária mulher/enfermeira que lhes permite escutar, sentir e intervir conjugando razão e emoção, bem como pelas especializações. A enfermeira da rede básica de saúde é comumente uma profissional que detém formação em saúde pública, área que defende mais enfaticamente a atenção às demandas bio-psico-sociais da clientela. Todavia, é necessário que, nos serviços de saúde, seja incentivado o trabalho interdisciplinar, "usando o intercâmbio e a complementariedade como alternativas ao individualismo"(14).

No serviço estudado, embora atendidas pelas enfermeiras sem restrições, as mulheres deparam-se com a ordem institucional que, freqüentemente, orienta suas práticas, segundo padrões convencionais de saber e poder. Isto porque, a prática médica, comprometida com a indústria farmacêutica e com a medicalização do corpo da mulher, comumente restringe-se à prescrição de contraceptivos hormonais orais, que se tornam regras:
O que me entristece no planejamento familiar, muitas vezes é você tá ali sentada, aí a paciente chega e diz: Qual é o comprimido que você tem aí? Ou chega com a receita pronta (...) como se a gente fosse mera entregadora de pílula (...). Quando a menina chega lá, e não tem conhecimento, a gente batalha pra que ela pelo menos descubra que existem outros métodos, além do comprimido e da camisinha (Eloísa).

O modo como a usuária dirige-se à enfermeira, no depoimento analisado, deve-se à cultura da pílula, reproduzida nos atos médicos que mantêm a medicalização do corpo da mulher e na facilidade com que as mulheres conseguem o contraceptivo hormonal oral em farmácias, o que é incorporado socialmente. Assim, no discurso de Eloísa, vê-se que o trabalho das enfermeiras é dificultado pelo isolamento entre os profissionais, que é explicado, inicialmente, pelo modelo biologicista de formação acadêmica que fragmenta os sujeitos/objeto da atenção, bem como as práticas profissionais. Somam-se a esse, desigualdades de gênero impostas pelo saber e pelo poder médico que resultam em dupla subordinação ao médico- a das mulheres enfermeiras e a das mulheres clientes. Estas geram situações conflituosas e competitivas, e, numa luta geralmente velada, vence o mais forte- o médico, pela hegemonia do saber e pela hegemonia masculina.

Wilma refere-se à desinformação das mulheres sobre a diversidade contraceptiva, ressaltando a sua reação diante do primeiro contato com informações novas:

\section{É que muitas são desinformadas sobre os métodos. Quando vêem o DIU, elas di- zem: Tudo isso? Eu vejo muito as mulhe- res assustadas quando a gente mostra todos os métodos, porque a maioria só conhece a camisinha e a pílula (Wilma).}

Relacionando o depoimento de Wilma ao analisado anteriormente e considerando que o uso de contraceptivos pelas mulheres é comumente decisão médica, estas são afastadas da possibilidade da escolha como exercício de liberdade. Isto nos permite afirmar que, a postura das mulheres frente à contracepção está condicionada a relações com sistemas de classe e de gênero, particularizados, nesta pesquisa, na relação com o serviço de saúde, detentor de um poder que ofusca a capacidade das mulheres de decidir sobre seu corpo, seus desejos e seus prazeres.
Atuação de enfermeiras no campo da regulação da fecundidade em um serviço público de saúde 
Edméia de Almeida C Coelho Rosa Maria G S Fonseca
Pesquisa realizada em serviços públicos de saúde na área geográfica em que se efetivou este estudo, demonstrou que em contracepção, as usuárias cumprem ordens médicas e mostram satisfação pela eficácia do anticoncepcional hormonal oral que também diminui conflitos com parceiros por não aceitarem usar preservativo, além de desconhecerem ou temerem usar outros métodos contraceptivos, sendo a camisinha o segundo mais conhecido e de uso circunstancial, a exemplo do período de amamentação. A satisfação com a pílula torna-se relativa, quando as clientes revelam que seu corpo é depositário de reações adversas, sendo a esterilização o que vislumbram no horizonte ${ }^{(15)}$.

Em síntese, na realidade estudada, o trabalho das enfermeiras é dificultado pela representação do planejamento familiar que permeia as instituições e também está inscrita no espaço social das mulheres. Considerando-se a organização das práticas em saúde e a implementação de políticas públicas, constata-se, nos discursos das enfermeiras, que o corpo das mulheres é usado arbitrariamente quando não são disponibilizados os métodos, em sua diversidade, para possibilitar sua escolha, de forma consciente, o que constitui uma forma de controle sobre seus corpos. Sob o prisma das desigualdades de classe, as práticas acabam encaminhando-se pelo assistencialismo, o que é facilitado quando se trata do trabalho das enfermeiras, que, orientadas por aprendizados de gênero, evocam atributos entendidos como femininos, para lidar com as clientes sem problematizar a realidade.

Eixo 2: Atividades educativas em planejamento familiar reproduzindo relações hegemônicas de classe e de gênero

A atuação profissional nas atividades educativas e clínicas de planejamento familiar deve respeitar subjetividades, ouvindo e discutindo com as mulheres suas experiências de vida e criando condições para que elas participem ativamente do processo de escolha contraceptiva. As atividades educativas devem ser preferencialmente em grupos e anteceder as atividades clínicas, possibilitando às mulheres, atuar como sujeitos capazes de decidir politicamente sobre o seu corpo e sua vida. Sendo assim, conforme reconhece o Ministério da Saúde, o conhecimento é construído respeitando-se a vivência e o saber de cada mulher, estando o profissional aberto para a troca de experiências e emoções, criando-se condições para se experimentar o mudar ${ }^{(16)}$.

Todavia, no serviço em que foi realizada a pesquisa, a aproximação das enfermeiras do contexto de vida das mulheres caminha ao lado das contradições da prática, o que pode ser constatado no depoimento a seguir, em que as enfermeiras não reagem ao monopólio do saber médico. Eloísa, ao ser procurada por uma cliente para mudança de contraceptivo (condom para contraceptivo hormonal oral), em uma situação representada pelo grupo, se exime da participação no processo da escolha contraceptiva, afirmando:

Para começarmos a consulta do planejamento familiar é o seguinte: Você tem que passar pela médica, fazer o exame citológico e pegar uma receita médica pra ver direito esses comprimidos (Eloísa).

Seguindo-se a esse discurso, a enfermeira mostra à cliente alguns anticoncepcionais disponíveis e a encaminha à consulta médica não aproveitando a oportunidade para criar um espaço de discussão com a mulher, que possibilite sua escolha não condicionada a decisões médicas, com encaminhamento posterior. Isso demonstra a incorporação e a reprodução do modelo de assistir em saúde, essencialmente vinculado ao saber e ao poder médico, bem como uma condição de dependência das enfermeiras. Desse modo, suas ações corroboram para a manutenção da ordem institucional, reduzindo as possibilidades de os serviços de saúde virem a se consolidar como espaço de transformação social.

No serviço em foco, o trabalho educativo é realizado, segundo as participantes do estudo, somente durante as consultas individuais, havendo trabalhos grupais no pré-natal com gestantes adolescentes. Wilma, referindo-se à prática educativa, afirma:

Eu tento passar pra ela da melhor forma possível, bem rastreiro, bem popular, para que ela entenda bem todos esses métodos, mas quando a gente demora muito nas informações, elas reclamam, como reclamam!... A gente quer passar aquilo bem pra elas, mas ... E as que ficam do lado de fora?! Isso aí vai até que horas? Soltam piadas, se a gente for dar ouvidos... (Wilma). 
Mas é porque a clientela é um povo tão sofrido... há mulheres que acordam às quatro horas da manhã (Valéria).

Elas vêm ao Posto para ir ao médico, se o médico falar, tudo bem. Mas, se nós falarmos..., a gente vai se aprofundar mais, elas não querem (Wilma).

Fica evidente nesse discurso, que as consultas individuais demandam tempo e, considerando-se que no serviço há apenas uma enfermeira responsável pelo planeja-mento familiar, em cada turno de trabalho, com alternâncias periódicas entre o grupo, fica defasado qualitativamente o trabalho com as mulheres. A clientela é referida como de mulheres pobres que moram longe e vêm de madrugada para o serviço de saúde. Possuem, portanto, poucos recursos para manter-se alimentadas durante as ausências dos domicílios e, muitas vezes, precisam contar com vizinhas ou parentes para os cuidados com os filhos, enquanto se deslocam até o serviço de saúde.

Há de se considerar, também, que a preocupação em passar informações é indicativa de uma postura onde o saber é unilateralizado e a relação, ao invés de atender às necessidades da clientela, pode distanciar-se delas, o que contradiz o discurso em que as mulheres são sujeitos ativos no processo da consulta de enfermagem. É importante valorizar que

todas as pessoas têm uma história pessoal e coletiva e um conhecimento sobre a sua realidade (...) ignorar estes elementos nos leva a estabelecer uma relação de aprendizagem que é de mão única- apenas do/a educador/a para o grupo - cujos resultados são muito mais precários do que a relação de mão dupla, que permite a identificação dos sujeitos com os conteúdos e apropriação dos conteúdos pelos sujeitos ${ }^{(17)}$.

Lívia posiciona-se em relação aos depoimentos anteriormente analisados e afirma:

Só as clientes mais novas, as adolescentes, não se interessam. Acho que as informações que elas queriam eram outras (Lívia).

No tocante às adolescentes,

ambos, sujeito-adolescente e sujeito-serviço, não precisamos apenas aprender a ouvir, mas especialmente, precisamos aprender a dizer. Temos falado e escutado uma única linguagem, uma linguagem técnico-científica que nos acena a possibilidade do diálogo, para privar-nos dela em seguida ${ }^{(18)}$.
É necessário

auscultar as outras necessidades dos adolescentes em seus processos de individuação/socialização (...) é essa ausculta que nos permite detectar demandas por informação, por espaços e temas para discussão e reflexão, por oportunidades de experimentar-se, por apoio para aventurar-se, por subsídios para defender-se contra opressões de ordem social, política, econômica, etc ${ }^{(18)}$.

Para Freire, a educação é uma atividade humana, que só cumpre o seu papel se proporcionar aos educandos os instrumentos que facilitem a criação de uma consciência crítica e,

qualquer que seja o nível em que se dê, se fará tão verdadeira quanto mais estimule o desenvolvimento da expressividade, que é uma necessidade radical do homem ${ }^{(19)}$.

E, ainda segundo Freire ${ }^{(20)}$,

o homem deve ser o sujeito de sua própria educação. Não pode ser objeto dela. Por isso ninguém educa ninguém.

A abordagem teórica de Paulo Freire, com algumas restrições, inclusive a de considerar o homem como sujeito único, é compartilhada pela perspectiva feminista e de gênero. No feminismo enfatiza-se a inter-relação constante entre identidade pessoal, social e coletiva, tendo como base a idéia de que a identidade pessoal é fortemente informada pelos padrões de gênero, que, por sua vez, irão influir, de modo decisivo, no modo como se constituem a identidade social e a coletiva das mulheres (...) por isso, privilegiam-se as microdimensões sociais sem se perder de vista sua relação com a dimensão macrossocial ${ }^{(17)}$.

No sentido de redirecionamento da prática educativa, Aline afirma:

Nós pensamos em fazer uma reunião por mês com o pessoal do planejamento familiar. Nós só fizemos uma até agora, sobre conhecimento do corpo, sobre os métodos, colocando todos em evidência e a questão das DST (Aline).

Considerando-se os fundamentos expostos sobre o processo educativo, no que tange ao planejamento familiar, cujas ações estão implantadas no serviço estudado há
Atuação de enfermeiras no campo da regulação da fecundidade em um serviço público de saúde 
Edméia de Almeida C Coelho Rosa Maria G S Fonseca quase duas décadas, há uma defasagem entre o que é proposto oficialmente e o que se faz. As consultas individuais são de importância singular, por proporcionarem à mulher um espaço de escuta, diálogo e particularização de realidades, porém, o trabalho educativo, quando em grupo e fundamentado em uma proposta participativa, é oportunidade para o compartilhamento dessas realidades, mobilizando subjetividades que também se coletivizam.

As atividades educativas devem ser integradas às práticas em saúde como processo político que objetive a mudança da relação das mulheres com os sistemas opressores, nestes incluídas as relações com os parceiros sexuais e com os serviços de saúde. Sendo assim, é preciso conhecer as mulheres e seus contextos de vida para se planejar as atividades temáticas, permitindo que estas sejam enriquecidas por conhecimentos individuais e coletivos.

\section{CONSIDERAÇÕES FINAIS}

No serviço em que foi realizada a pesquisa, a autonomia das enfermeiras para enfrentamento de problemas no âmbito da saúde sexual e reprodutiva é comprometida por questões macroestruturais e pelo monopólio médico, o qual faz o serviço se organizar segundo seus critérios e prioridades, o que é reproduzido na prática das enfermeiras. Além disso, o trabalho com mulheres, nesse campo, está condicionado a representações culturais que controlam e medicalizam seu corpo e o submetem às regras do mercado.

As enfermeiras, por sua vez, ao se calarem diante do poder institucional/médico, submetem-se a ambos, numa demonstração de que incorporaram e reproduzem, no campo de práticas, o modelo de formação acadêmica, vinculado às estruturas de poder do Estado que naturalizam subordinações. As enfermeiras acabam por reproduzir desigualdades, fazendo da necessidade das mulheres um espaço de exercício do poder institucional, historicamente construído e consolidado no masculino. Entretanto, as relações de poder diluem-se nas tantas outras estabelecidas e, certamente, pela formação da identidade profissional, articulada ao papel que a sociedade dá à mulher, a enfermeira relaciona-se com as mulheres clientes de forma menos reducionista.
Assim, pela atuação das enfermeiras, as mulheres usuárias têm acesso a informações e aos métodos contraceptivos por um processo menos verticalizado, mas, os recursos para a construção de sua autonomia e liberdade reprodutiva são escassos. As razões estão ligadas à forma pela qual o serviço orienta as ações em contracepção e à realidade social das mulheres estruturada em meio a desigualdades de classe e de gênero que permeiam sua vida e as relações que estabelecem com os serviços de saúde.

Neste estudo, as enfermeiras relevam a sua prática, ao mesmo tempo em que contestam a realidade, presas a um referencial de saber que compromete seu empoderamento. Faz-se necessário que lhes seja possibilitada a inserção em atividades de reflexão e de discussão sobre a prática, de modo que experiências individuais possam ser coletivizadas e, no confronto com as realidades micro e macro estruturais criem-se instrumentos para se pensar mudanças.

Em relação à atuação das enfermeiras junto às mulheres usuárias dos serviços de planejamento familiar, a inclusão de práticas educativas participativas nas prioridades da atenção deve ser incentivada como meio de se valorizar o contexto de vida, o saber e a experiência das mulheres, possibilitando a vinculação das usuárias ao serviço, sem a referência do modelo biomédico. Assim, vislumbrar-se-á uma aproximação da prática das enfermeiras com a perspectiva da saúde sexual e reprodutiva, em que as mulheres têm acesso aos meios que lhes garantem as possibilidades de uma gravidez bem-sucedida e os casais são capazes de ter relações sexuais, sem medo de gravidezes indesejadas e de contrair doenças ${ }^{(21)}$. Particularizando-se as relações enfermeiras-clientes, estas só serão emancipatórias se buscarem, por meio de intenções e práticas, criar espaços para as mulheres fazerem-se sujeitos da história e, como diz Paulo Freire, fazer a história e não, simplesmente, serem arrastadas por ela. 
(1) Coelho EAC. Enfermeiras que cuidam de mulheres: conhecendo a prática sob o olhar de gênero. [tese] São Paulo (SP): Escola de Enfermagem da USP; 2001.

(2) Coelho EAC. Política de planejamento familiar em João Pessoa - PB: análise das contradições existentes entre o discurso oficial e a prática. [dissertação] João Pessoa (PB): Universidade Federal da Paraíba; 1996.

(3) Coelho EAC, Lucena MFG, Silva ATM. Política de planejamento familiar no Brasil no contexto das políticas públicas de saúde: determinantes históricos. Rev Esc Enferm USP 2000; 34(1): 37-44.

(4) Coelho EAC, Lucena MFG, Silva ATM. Política de planejamento familiar no Brasil no contexto das políticas públicas de saúde: determinantes históricos. Rev Esc Enferm USP 2000; 34(2): 119-27.

(5) Meyer DE, Waldow VR; Lopes MJM, organizadoras. Marcas da diversidade: saberes e fazeres da enfermagem contemporânea. Porto Alegre: Artmed; 1998. Apresentação; p. 7-8.

(6) Minayo MCS, organizadora. Pesquisa social: teoria, método e criatividade. $16^{\mathrm{a}}$ ed. Petrópolis: Vozes; 1999.

(7) Coelho EAC, Fonseca RMGS, Silva MSS, Silveira MFA. Oficinas de reflexão: alternativa metodológica para a pesquisa em enfermagem e saúde da mulher. In: Anais do $2^{\circ}$ Encontro Internacional de Pesquisa em Enfermagem; 2000 out 28-31; Águas de Lindóia.[CD-ROM]. São Paulo: EEUSP; 2002.

(8) Viezzer M. Educação popular e movimento de mulheres: oficina de metodologia. São Paulo: Rede Mulher; 1987.

(9) Fiorin JL. Linguagem e ideologia. $6^{\mathrm{a}}$ ed. São Paulo: Ática; 1998.

(10) Fiorin JL, Savioli FP. Para entender o texto: leitura e redação. $15^{\text {a }}$ ed. São Paulo: Ática; 1999.

(11) Fiorin JL. Elementos de análise de discurso aplicados à pesquisa em Enfermagem. São Paulo; 2000. [Apostila do Curso sobre Elementos de Análise de Discurso aplicados à Pesquisa em Enfermagem - Escola de Enfermagem da USP].
(12) Ministério da Saúde. Centro de Documentação. Assistência ao planejamento familiar: normas e manuais técnicos. Brasília; 1987.

(13) Valladares DP. Ações de contracepção e assistência ao parto: a experiência do Rio de Janeiro. In: Giffin K, Costa $\mathrm{SH}$, organizadoras. Questões de saúde reprodutiva. Rio de Janeiro: FIOCRUZ; 1999. p. $357-76$

(14) Lima MJ. Desafio de hoje: o desenvolvimento de profissionais de enfermagem - uma década de trabalho com criatividade, sensibilidade e expressividade. In: Meyer DE, Waldow VR, Lopes MJM, organizadoras. Marcas da diversidade: saberes e fazeres da enfermagem contemporânea. Porto Alegre: Artmed; 1998. p. 103-25.

(15) D'Oliveira AFPL, Schraiber LB. Violência de gênero, saúde reprodutiva e serviços. In: Giffin K, Costa SH, organizadoras. Questões de saúde reprodutiva. Rio de Janeiro: FIOCRUZ; 1999. p.337-56.

(16) Ministério da Saúde. Centro de Documentação. Manual do Coordenador de Grupos de Planejamento Familiar: normas e manuais técnicos. Brasília; 1987.

(17) Portella AP, Gouveia T. Idéias e dinâmicas para trabalhar com gênero. Recife: SOS Corpo; 1998.

(18) Ayres JRCM, França Júnior I. Saúde do adolescente. In: Schraiber LB, Nemes MIB, Mendes-Gonçalves RB. Saúde do adulto: programas e ações na unidade básica. $2^{\mathrm{a}} \mathrm{ed}$. São Paulo: Hucitec; 2000. p. 66 - 75.

(19) Freire P. Conscientização: teoria e prática da libertação. 3 a ed. São Paulo: Moraes; 1980.

(20) Freire P. Educação e mudança. $16^{\mathrm{a}}$ ed. Rio de Janeiro: Paz e Terra; 1990.

(21) Galvão L. Saúde sexual e reprodutiva, saúde da mulher e saúde materna: a evolução dos conceitos no mundo e no Brasil. In: Galvão L, Díaz J, organizadores. Saúde sexual e reprodutiva no Brasil. São Paulo: Hucitec; 1999. p.165-79.
Atuação de enfermeiras no campo da regulação da fecundidade em um serviço público de saúde 